\title{
PRÁTICAS EDUCATIVAS EM SAÚDE E A CONSTITUIÇÃO DE SUJEITOS
} ATIVOS

\author{
Rogério Dias Renovato ${ }^{1}$, Maria Helena Salgado Bagnato ${ }^{2}$
}

\begin{abstract}
${ }^{1}$ Doutor em Educação. Professor Adjunto do Curso de Enfermagem da Universidade Estadual de Mato Grosso do Sul. Mato Grosso do Sul. Brasil. E-mail: rrenovato@uol.com.br

${ }^{2}$ Doutora em Educação. Professora Livre-docente da Faculdade de Educação da Universidade Estadual de Campinas. São Paulo, Brasil. E-mail: mbagnato@unicamp.br
\end{abstract}

RESUMO: O objetivo do artigo é problematizar as práticas educativas em saúde contemporâneas e suas contribuições na constituição de subjetividades. Trata-se de um estudo teórico-reflexivo, procurando cotejar essas práticas com as concepções foucaultianas de segurança e liberdade, elementos-chave na fabricação do sujeito ativo. Para esse percurso reflexivo abordamos a interdependência dessas práticas com a biomedicina e seus enunciados, em conformidade com a filosofia do risco, bem como a capilarização desses discursos através das pedagogias culturais. Sendo assim, entendemos que essas práticas podem apresentar várias configurações, dentre elas as estratégias provenientes dos dispositivos de segurança, que contribuem para a formação de sujeitos ativos. Nesses emaranhados discursivos, entrelaçados por inúmeras dimensões, por práticas de saúde construídas historicamente, não se pode mais imaginar relações de poder binarizadas, e sim, múltiplas relações de poder entremeadas de interpelações, que delimitam condutas consideradas saudáveis para esse outro, alicerçadas em representações situadas em espaços e temporalidades particulares.

DESCRITORES: Educação em saúde. Cultura. Risco. Identidade.

\section{EDUCATIONAL PRACTICES IN HEALTH CARE AND THE CONSTITUTION OF ACTIVE SUBJECTS}

\begin{abstract}
The objective of this article is to identify the problems of contemporary educational practices in health care and their contributions to the constitution of subjectivities. This is a theoretical, reflexive study, seeking to articulate these practices within Foucaultian conceptions of safety and freedom, key elements in manufacturing an active subject. In this reflexive examination we address the interdependence of these practices with biomedicine and its proclamations in conformity with risk philosophy, as well as the capillarization of these discourses of the active subject through cultural pedagogies. Thus, we understand that these educational practices could present many configurations, among them strategies originating from safety devices, which contribute to the formation of active subjects. In this tangle of discursive elements, interlaced by innumerous dimensions, by historically-built health practices, one can no longer imagine binary power relationships, but multiple power relationships intermingled with interpellations, which delimit conducts considered healthy for this other, grounded in representations situated in particular spaces and temporalities.
\end{abstract}

DESCRIPTORS: Health education. Culture. Risk. Identity.

\section{PRÁCTICAS EDUCATIVAS EN SALUD Y LA CONSTITUCIÓN DE SUJETOS ACTIVOS}

RESUMÉN: El objetivo del artículo ha sido problematizar las prácticas educativas en salud y sus contribuciones para la constitución de subjetividades. El presente es un estudio teórico-reflexivo, donde se busca cotejar las prácticas con las concepciones foucaultianas sobre seguridad y libertad, elementos claves en la creación del sujeto activo. Para realizar esa reflexión, se aborda la interdependencia de las prácticas educativas en salud con la biomedicina y sus enunciados en conformidad con la filosofía del riesgo, así como la capilaridad de esos discursos sobre el sujeto activo a través de las pedagogías culturales. De esa forma, se entiende que esas prácticas educativas pueden presentar varias configuraciones, entre ellas, estrategias provenientes de los dispositivos de seguridad, que contribuyen para la formación de sujetos activos. En ese enmarañado de elementos discursivos, entrelazados por innumerables dimensiones, por prácticas de salud construidas históricamente, no se puede más imaginar relaciones de poder polarizadas sino, múltiples relaciones de poder intercaladas por interpelaciones que delimitan conductas consideradas saludables para ese otro, fundamentadas en representaciones situadas en espacios y temporalidades particulares.

DESCRIPTORES: Educación para la salud. Cultura. Riesgo. Identidad. 


\section{INTRODUÇÃO}

Nas trilhas das histórias sobre as Práticas Educativas em Saúde (PES) no Brasil, vários discursos foram pronunciados em nome de uma consciência sanitária, na busca pela identidade nacional, ou na tentativa de romper com o ciclo da miséria e das doenças presentes. Esses discursos singulares e particulares assumiram sentidos múltiplos e tiveram seus representantes: em geral, os profissionais de saúde e da educação, podendo ter contribuído na formação de identidades de homens, mulheres, crianças e idosos em espaços e tempos específicos.

Porém, em determinados períodos históricos, as PES "[...] se prestaram muito mais para regular, controlar e disciplinar homens e mulheres, para um certo modelo de sociedade, para um projeto civilizatório[...]". 1:88 Então, quais as contribuições das PES contemporâneas na constituição de subjetividades?

Nessa dispersão de pensamentos em movimento, consideramos oportuno, através desse estudo teórico e reflexivo sobre as PES, aproximarmos-nos do pensamento foucaultiano, mais especificamente do segundo percurso genealógico do biopoder, cuja noção de poder não está vinculada somente à ação exercida sobre um corpo com a finalidade de discipliná-lo, mas sim, sobre a ação que se exerce sobre outra ação. Desde então, o exercício de poder não age direta e imediatamente sobre os outros: trata-se de uma ação sobre a conduta, seja ela, eventual, presente ou futura. Neste deslocamento, o sujeito docilizado, passivo e dominado cede espaço ao sujeito ativo, que é capaz de cuidar de si. A liberdade de ação é condição indispensável para essa nova especificidade do biopoder. ${ }^{2}$

Na contemporaneidade, a cultura ocidental tem enfocado com veemência o gerenciamento de si, o autogoverno de seus corpos e o autocuidado em saúde, como elementos de autonomia e sucesso, contribuindo com processos de subjetivação, e na formação de novas matrizes identitárias, como a constituição de sujeitos ativos.

Desse modo, o objetivo desse estudo teóricoreflexivo foi problematizar as práticas educativas em saúde contemporâneas e suas contribuições na constituição de subjetividades. O percurso metodológico constituiu-se na aproximação com as concepções foucaultianas sobre segurança e liberdade, elementos-chave na fabricação do sujeito ativo, bem como na abordagem da interdependência das PES com a biomedicina e seus enunciados, em conformidade com a filosofia do risco. E, por fim, a capilarização desses discursos sobre o sujeito ativo através das pedagogias culturais.

Para realizarmos estes diálogos assumimos, neste texto, que as PES são práticas sociais, culturais e detentoras de racionalidades e significados históricos. As PES envolvem intencionalidades educativas, não se restringindo às informações, orientações e ações com ênfase somente na técnica, mas são processos que ocorrem no encontro entre pessoas com diferentes culturas e realidades sociais e econômicas, com representações diversas sobre a saúde, e as formas de ser e estar saudável. ${ }^{1}$

\section{SEGURANÇA-LIBERDADE: POLÍTICAS, ESTRATÉGIAS E TECNOLOGIAS DA GOVERNAMENTALIDADE NA CONS- TRUÇÃO DO SUJEITO ATIVO}

As concepções de segurança e liberdade foram apresentadas em curso ministrado por Michel Foucault, no Collège de France, de 11 de janeiro a 5 de abril de 1978, que teve como título "Segurança, território e população". Ao longo do evento, à medida que o filósofo francês analisava o liberalismo do século XVIII, propôs como categoria de análise, a segurança, pois, segundo ele, essa questão foi inserida na nova racionalidade de governo. ${ }^{3}$

Em sua aula inicial, Foucault chama a atenção para o conjunto de mecanismos que transformaram as características biológicas do ser humano em objeto de estratégia política, de estratégia geral de poder. Além do mecanismo da disciplina, já conhecido e estudado pelo autor, o conceito de segurança emerge como um dispositivo que se aproxima do campo da probabilidade. Este não vem cancelar ou anular as estruturas jurídico-legais e, muito menos os mecanismos disciplinares. Ao contrário, o(s) dispositivo(s) da segurança acontece(m) em e no conjunto desses fenômenos.

Na nova racionalidade de governo, os referidos dispositivos, em consonância com os mecanismos de intervenção do Estado, vão assegurar e regular os processos econômicos, os fenômenos naturais e os processos intrínsecos da população. Desse modo, Foucault propõe o estabelecimento de uma relação que se torna inseparável: o par segurança-liberdade. ${ }^{3}$ Por conseguinte, a liberdade é o meio que circunda esse novo espaço de governo, a população. O desrespeito à liberdade não é simplesmente uma violação ilegítima dos direitos, mas a ignorância em como governar. ${ }^{4}$ 
Segundo Foucault, os dispositivos de segurança e as tecnologias decorrentes podem se constituir em mecanismos de controle social, que se integram com outros elementos como a psicologia, comportamento, modos de fazer e produzir as coisas, consumidores, comércio, marketing e, ao mesmo tempo, se organizam e estabelecem novas relações, outros circuitos. ${ }^{3}$

Os dispositivos de segurança não delimitam espaços rígidos e são flexíveis, permitem a mobilidade em um intervalo, não se restringem a uma relação binária, e sim, ao conjunto de pertinências, de possibilidades, de regulação de processos naturais, de controle de fenômenos epidêmicos, de organização de espaços urbanos. ${ }^{5}$ Em outras palavras, a lei proíbe, a disciplina prescreve e a função essencial da segurança, sem proibir ou prescrever, porém utilizando alguns instrumentos legais e disciplinares, é responder a fatos da realidade, de tal modo que sua resposta anule os elementos dessa realidade que desencadearam esses dispositivos.

Logo, podemos afirmar que os dispositivos de segurança envolvem uma série de eventos que são possíveis e prováveis, utilizam-se de ferramentas de cálculo para comparar e avaliar custos e sua especificação percorre um intervalo aceitável e pertinente, não se restringindo ao binarismo dos mecanismos disciplinares. ${ }^{4}$

Ao final da quarta aula, em $1^{\circ}$ de fevereiro de 1978, conhecida como a Governamentalidade, Foucault diz ser a segurança, um movimento que avança diante da moderna racionalidade de governo. Desse modo, "[...] esse Estado de governo que tem essencialmente como alvo a população e utiliza a instrumentalização do saber econômico, corresponderia a uma sociedade controlada pelos dispositivos de segurança [...]". 6:293 Desde então, passou-se a viver em uma sociedade de segurança, em coexistência com uma sociedade de direito ou disciplinar já instauradas.

Em relação ao componente liberdade, Foucaul $t^{3}$ propõe que a liberdade deve ser compreendida neste universo de mudanças e transformações de tecnologias de poder. A liberdade está correlacionada à aplicação dos dispositivos de segurança, pois eles só poderiam atuar e operar em condições de liberdade, possibilitando movimento, mudanças de posição e processos de circulação de coisas e pessoas. E de modo inusitado, Foucault propõe que a liberdade nada mais é que uma tecnologia de poder: "[...] first of all and above all it is a technology of Power $[\ldots]$...:4:49
A liberdade, em Foucault, pode ser considerada como uma tecnologia da governamentalidade, contrapondo-se à idéia de uma liberdade essencialista, todavia atrelada a mecanismos de submissão ética, como o olhar normativo dos outros, o trabalho disciplinar de agências estatais ou não. Assim, ser livre seria conduzir sua existência, a sua conduta, a partir da relação de si com os outros ou consigo mesmo, de relações de poder, que, cada vez mais, impõem outros constrangimentos, diferentes dos mecanismos disciplinares, favorecendo a criação de cidadãos, como condição primeira do seu efetivo exercício nas sociedades liberais. ${ }^{7}$

O que se pretende desde então é perguntar como as novas estratégias de governamentalidade podem construir novas subjetividades, neste caso, o sujeito ativo. Qual seria a relação com as concepções de segurança e de liberdade em sociedades, cuja tecnologia de governo nunca deixou de ser liberal, muito menos cessou de estar obcecada pelo liberalismo, desde o final do século XVIII? Tomaz Tadeu da Silva afirma que as tecnologias que produzem tais subjetividades são a condição de governamentalização do Estado. Isto é, “[...] mais autonomia significa também mais governo (no sentido de controle da conduta) ou [...] mais cidadania significa também mais regulação $[\ldots]^{\prime \prime} .8: 8$

Assim, entendemos que a constituição de sujeitos ativos são processos históricos de mecanismos de sujeição, formas de poder que se aplicam à vida cotidiana imediata, marcando esses sujeitos em suas próprias individualidades, impondo efeitos ou jogos de verdade, os quais devem ser reconhecidos e que os outros têm de reconhecer neles. Para Foucault, a construção dessas subjetividades envolve relações complexas e circulares com outras formas, uma combinação astuciosa de técnicas de individualização (ou tecnologias de si) e de procedimentos de totalização (estados de dominação). ${ }^{9}$

Foucault situa as tecnologias de governamentalidade entre as tecnologias de si e as tecnologias de dominação, como estratégias que operam sobre o campo de possibilidades onde se inscreve o comportamento dos sujeitos ativos. Isto é, conduzir a conduta do outro é agir sobre um ou vários sujeitos ativos, governando assim, um eventual campo de ação dos outros.

Os atos ou as condutas são os verdadeiros comportamentos das pessoas em relação aos códigos ou prescrições impostos aos sujeitos. A fa- 
bricação de sujeitos ativos na contemporaneidade pode evocar quatro aspectos principais: o aspecto desse sujeito ou o comportamento relacionado à conduta e o que é concebido como ser indivíduo ativo, sua substância ética. O segundo aspecto é o modo de sujeição descrito anteriormente, que se constitui na maneira pelo qual as pessoas são chamadas ou incitadas a se reconhecerem como ativas. O terceiro inclui as práticas de ascese, que são os meios pelo quais esses sujeitos podem se modificar para se tornarem sujeitos. E o último aspecto, qual o tipo de ser a que aspiramos, quando nos comportamos como sujeitos ativos. Foucault chama esses quatro aspectos acerca da constituição de subjetividades - sua ontologia, sua deontologia, sua ascética e sua teleologia. ${ }^{10}$

Portanto, é possível afirmar que o sujeito ativo é fabricado, assim como foi o sujeito passivo e docilizado ou, nas palavras de Foucault: “[...] eu diria que, se agora me interesso de fato pela maneira como e qual o sujeito se constitui de uma maneira ativa, através de práticas de si, essas práticas não são, entretanto, alguma coisa que o próprio indivíduo invente. São esquemas que ele encontra em sua cultura e que lhe são propostos, sugeridos, impostos por sua cultura, sua sociedade e seu grupo social $[\ldots]^{\prime \prime} .11: 276$

Assim, não se trata agora da coerção e dos constrangimentos exercidos sob a massa dos governados, já que "[...] o poder liga-se antes aos modos como, numa dinâmica onde a autonomia e liberdade estão cada vez mais presentes [...]", 7:31 mas também, sobre a produção de cidadãos, não apenas destinatários, mas "[...] intervenientes nos jogos e nas operações de poder [...]". 7:31

Ao sujeito contemporâneo, o desenvolvimento da cultura de si criou indivíduos sob a crença: pertence-se a si, só depende de si mesmo, que buscam combater qualquer possibilidade de fraqueza e fragilidade, com base em princípios universais, provenientes da razão ou da ciência, tendo como profetas, os especialistas, cuja teleologia é a soberania do sujeito sobre ele próprio. Assim, como vigilante censor de si mesmo, o sujeito ativo aplica-se sobre si práticas de ascese, que interpelam as subjetividades que circulam, sob a égide do capitalismo tardio, da valorização excessiva do corpo e da busca contínua pela saúde perfeita.

Consequentemente, "[...] à medida que um maior número de pessoas sintoniza a sua conduta com a de outros, a teia de acções vai se organizando igualmente de forma mais pertinente, porque assenta essencialmente numa economia caracterizada por autocoações. De outra forma, os mecanismos de controlo individual são uma resposta ao aumento de densidade e complexidade das networks sociais [...]".7:72

No curso oferecido por Michel Foucault, em 1979, sob o título "Nascimento da Biopolítica", o autor já apresenta algumas análises sobre o neoliberalismo e aponta para uma nova tecnologia de governo que, em vez de se caracterizar apenas pelo afrouxamento ou minimização do Estado, passa a estabelecer novas responsabilidades e a conduzir novas ações em conformidade com modelos apropriados, nos quais os governados são encorajados, livre e racionalmente, a se conduzirem a si. ${ }^{12-13}$

Na perspectiva do neoliberalismo, a liberdade do sujeito é uma condição para a sua sujeição, visto que o exercício da autoridade pressupõe a existência de um sujeito livre, tornando possível o processo de conformação e moldagem em matrizes identitárias, que fazem esses sujeitos capazes de exercitar suas liberdades. ${ }^{14}$ São estratégias de autonomização de sociedades, práticas de liberdade que se materializam em formas ativas, como o exercício do consumo, auto-ajuda, mudança de estilo de vida, emoldurados em um conjunto de regras, normas, indicadores e conselhos de especialistas, que se capilariza a partir de artefatos pedagógicos, como as revistas, TV, jornais, internet, rádio e em outros espaços e temporalidades que afloram as pedagogias culturais.

Tendo em vista os deslocamentos dessas outras racionalidades de governo, percebem-se novos e outros mecanismos de poder e novas e outras relações que acercam as concepções de segurança e liberdade. A fabricação do sujeito ativo, sujeito independente, sujeito de si, autor de suas próprias escolhas, colige para o sujeito que se responsabiliza pelos riscos e perigos que essas escolhas implicam. A relação entre segurança e liberdade se transformou e se acentuou, após a Segunda Guerra Mundial, com a criação de instituições de segurança social, capazes de capitalizar os riscos e a segurança, mensurá-los e estabelecer relações de probabilidade, promulgando a lenta dissolução das atribuições do Estado em prol do cidadão responsável. $^{2}$

Nesta etapa histórica contemporânea, não linear e singular em cada Estado-nação, mas que avança em diferentes níveis de intensidade, a busca conjunta de segurança e liberdade presencia um impasse que transfere aos sujeitos 
independentes a responsabilidade por suas vidas, sua trajetória profissional, sua saúde, além dos riscos assumidos e das conseqüências decorrentes. O que se espera desses sujeitos ativos é que eles sejam capazes de construir o seu curso de vida, a partir de suas escolhas. Suas decisões e aspirações são conduzidas por componentes inteligíveis para si e para os outros, isto é, uma busca universal por valores definidos pelas sociedades contemporâneas, garantindo satisfação e realização de si para si. ${ }^{15}$

O sujeito ativo é o indivíduo independente e livre, capaz de fazer suas escolhas, mas também de se responsabilizar pelo ônus das decisões tomadas ao longo de sua vida. Assim, com a ascensão do conceito de segurança desde o século XVIII, concretiza-se a passagem do nível de uma microfísica para um nível biopolítico. Com efeito, "[...] o risco é para a segurança, o que a norma é para as disciplinas, sendo a categoria do risco, categoria constitutiva da segurança, o exacto homólogo da norma disciplinar $[\ldots]^{\prime \prime} .{ }^{16: 88}$ Assim, a filosofia do risco se apresenta entremeada de repertórios discursivos, construídas ao longo da modernidade, em que o risco é um princípio de objetivação e em estreita relação com o conceito de segurança.

Logo, a adoção de comportamentos saudáveis, como dietas alimentares e práticas de exercícios físicos implicam práticas que constroem identidades, produzem indivíduos que continuamente se autovigiam. São tecnologias de segurança, tecnologias governamentalizadas pautadas no autogoverno e regidas pela filosofia do risco. São práticas de controle incentivadas pelo Estado e também pela sociedade. São processos de reregulação inseridos em um contexto permeado de flexibilidade e liberdade, que se materializa pelo refinamento de novas estratégias de vigilância. Afinal, são práticas que têm na ontologia da segurança, os componentes nucleares dos processos de subjetivação.

Na formação dos sujeitos ativos, algumas dimensões ou facetas podem ser problematizadas e qualificadas. Não se propõe aqui uma única concepção de sujeito, mas a possibilidade de outros sujeitos, descentrados, que são atravessados por elementos, como a prudência, o empreendedorismo e a performatividade. Tais componentes poderiam em maior ou menor escala integrar as ações constitutivas dos discursos veiculados nas PES, permeadas pela ótica do sujeito biológico, que tem sua subjetividade delimitada e inventada pela biomedicina, seus parâmetros e indicadores, seu corpus, suas tecnologias e tentativas de dimensionar outras e novas identidades. ${ }^{17}$

\section{AS PRÁTICAS EDUCATIVAS EM SAÚDE E A BIOMEDICINA}

As práticas educativas em saúde têm sua trajetória histórica vinculada à biomedicina, sendo construída em conformidade com as pespectivas dessa racionalidade. A biomedicina pode ser delineada nas seguintes proposições: tem caráter generalizante, não se ocupando de casos individuais; visa à objetivação do corpo, das lesões e das doenças, sob a ótica do corpo-máquina; e tem como finalidade a elucidação das verdades ou leis gerais, com base em abordagem teórica e instrumental. ${ }^{18}$

$\mathrm{O}$ paradigma da biomedicina teve e tem como elemento nuclear a doença. As doenças e suas classificações são realizadas a partir da visualização das lesões, que parecem se comportar como seres autônomos. Assim, as PES, pelo seu caráter teleológico decorrente, são conduzidas com a finalidade de manter esse corpo saudável e livre de doenças.

Como racionalidade fundamentada no saber científico, seu incremento foi ampliado pelas tecnologias instrumentais, intensificando o processo de decomposição do conhecimento, por meio de uma perspectiva analítica. Logo, para o aprofundamento desse saber, a biomedicina passou a dar ênfase nas partes, a fim de se conhecer a totalidade.

A insinuação desses discursos e a sua legitimação através de espaços formais, como os hospitais e as universidades, garantiram aos seus seguidores suas práticas e a organização do exercício de suas atividades, a possibilidade de desautorizar e desqualificar "[...] outros discursos e outras práticas, de modo a se projetarem nos diferentes estratos da sociedade, como autoridades portadoras de um conhecimento suficiente e necessário para regular tanto a vida do indivíduo, como a ordem social $[\ldots]^{\prime \prime}{ }^{19: 31}$

Se a biomedicina constituiu-se como legítima ciência, no processo de condução do comportamento individual e ordenamento social, seu domínio sobre a sociedade e seu cotidiano, por intermédio do processo de medicalização, em vez de promover a autonomia do ser humano sem saúde, alimentou sua dependência, reivindicou submissão, criando mais necessidades, e o 
controle pelo outro-especialista, que interpreta e intervém em seu corpo. ${ }^{20}$

Desse modo, as PES, de maneira geral, parecem reproduzir os discursos da biomedicina, como a dicotomia entre a doença do ponto de vista do profissional de saúde e a doença do doente, que pode não se enquadrar na objetividade do diagnóstico, mas é permeado pelas vivências, pelas sensações e pelos sentidos desses doentes. Essa racionalidade médica tende a não considerar as singularidades, pois fundamentada em uma perspectiva sócio-histórica, constituiu-se como a mais social das disciplinas modernas, "[...] que institui e normaliza estruturas de relações sociais a partir de enunciados naturais típicos do seu campo de objetivações [...]". ${ }^{21: 31}$

A biomedicina, nos escritos de Foucault, ${ }^{6}$ é concebida como uma estratégia biopolítica capaz de tecer articulações entre os dispositivos disciplinares e a regulamentação da população. Desse modo, a existência biológica dos seres humanos tornou-se questão política de várias maneiras. ${ }^{22}$ Com o aprimoramento das tecnologias e dos recursos matemáticos foi possível estender o aparato médico não apenas sobre a lesão já estabelecida, mas a partir dos fatores de risco, prever lesões ainda silenciosas, detectadas por relações abstratas de causalidade. Essa constante vigilância sobre o corpo e sobre as proto-lesões possibilitaria, ao longo do tempo, detectar precocemente um quadro patológico. Porém, suas certezas estariam sempre envoltas pela volatilidade do futuro, em que outras variáveis poderiam ou não interferir na manifestação dessa doença.

Logo, a biomedicina da vigilância, que se fundamenta no discurso do risco, investe cada vez mais, na busca pela prevenção do indivíduo, não apenas na fabricação de outros espaços, mas se estende em outras temporalidades, em que o acompanhamento ao longo da vida preconiza a perpetuação do biopoder que investe sobre o corpo social, de modo individualizante e totalizante.

Baseada no discurso de risco, a biomedicina incorpora diferentes estratégias biopolíticas, em que a distinção binária entre normal e patológico passa a ser organizada em tecnologias de governamento do risco. Essas tecnologias atingem vários níveis, entre os quais, o gerenciamento de grupos de alto risco, por meio de sua identificação pela epidemiologia e a intervenção pautada em modelos preventivistas.

A concepção de saúde oriunda desse modelo de racionalidade médica é constituída por atribuições morais, cuja responsabilidade pela manutenção desse estado saudável é fomentada pelo acesso que esse indivíduo tem ao conhecimento, assegurando-lhe meios de se autovigiar, prevenir e avaliar os possíveis riscos. O sujeito ativo também assume o papel de consumidor dos serviços biomédicos, que contribuem para manter seu corpo saudável.

Assim, a biomedicina contemporânea pode se utilizar das PES como instrumentos de reprodução de seus discursos, entremeados de interesses políticos e econômicos, que circulam efeitos de verdade e constroem subjetividades e identidades, a partir do avanço das novas tecnologias biomédicas, da distribuição e consumo dos saberes biomédicos. Todavia, o processo de medicalização atual não é pré-determinado, e sim, contingente, refletindo relações de poder e saber, que se transformam, sofrem interferências e apresentam contradições. ${ }^{23}$

\section{AS PRÁTICAS EDUCATIVAS EM SAÚDE E AS PEDAGOGIAS CULTURAIS}

$\mathrm{Na}$ contemporaneidade, as PES não se restringem apenas aos espaços formais das escolas e dos serviços de saúde, mas atravessam outros territórios, fazendo circular discursos, com intencionalidade educativa, através de outros artefatos pedagógicos, como as pedagogias culturais. Ou seja, "[...] todos os locais de cultura em que o poder se organiza e se exercita, como programas de TV, filmes, jornais, revistas, brinquedos, catálogos, propagandas, anúncios, videogames, livros, esportes, shopping centers, entre tantos outros, são espaços que educam, praticando pedagogias culturais que moldam nossa conduta $[\ldots]]^{\prime \prime} \cdot{ }^{24: 144}$

As pedagogias culturais trazem a pletora de discursos na forma de artefatos, que funcionam como mecanismos de representações e, ao mesmo tempo, operam nos processos identitários. “[...] Os discursos utilizados nesses artefatos culturais difundem certos modelos de educação em saúde e cidadania, colaborando para a construção e a produção de sentidos, significados, relações de poder e para a constituição de sujeitos em certos tempos e espaços [...]". 25:166

Em relação à capilarização das concepções do sujeito ativo, campanhas educativas em saúde têm se utilizado de artefatos culturais para reforçar o autogoverno, conforme verificado nos estudos referentes às campanhas de prevenção à aids, ${ }^{26} \mathrm{de}$ 
combate ao tabagismo ${ }^{27}$ e de prevenção e manutenção de saúde do olho. ${ }^{28}$

Em estudo sobre o papel das campanhas de prevenção à aids veiculadas na TV observou-se o enfoque sobre o indivíduo e seu autocuidado, orientando sua conduta e suas práticas. ${ }^{26}$ Desse modo, pode-se perceber estratégias de governamentalidade, em que os discursos veiculados procuram reforçar a filosofia do risco, que se fundamenta, não apenas na ciência biomédica, mas também na ontologia do par segurança-liberdade. A expectativa é proteger a população com ações individuais, implementar a ascese corporal e o governo sobre a vida.

Sobre a campanha de combate ao tabagismo, as imagens veiculadas nos cigarros interpelam os sujeitos, usuários do tabaco, conclamando-os à adoção da abstinência e, simultaneamente, reforçam o discurso moralizante e classificatório, que separa bons de maus. Essa estratégia biopolítica que, mais uma vez, considera apenas as dimensões individuais, encontra seu respaldo na biomedicina, e assim, as PES, veiculadas através de artefatos culturais, circulam as concepções do sujeito ativo aquele que sabe cuidar de si e, portanto, classifica, rotula e condena os ineptos e incapazes de vencer a dependência nicotínica. ${ }^{27}$

Sobre a campanha de prevenção e manutenção da saúde visual, a análise realizada ${ }^{28}$ corrobora os achados anteriores e encontra eco em pesquisa que estudou os materiais pedagógicos inseridos no Programa Nacional de Saúde do Escolar. ${ }^{29}$ Para esse estudo, os artefatos são estratégias de governamentalidade, produzindo normas e estabelecendo padrões. ${ }^{29}$ Porém, percebe-se certo deslocamento da vigilância disciplinar para uma gestão privada de riscos. O autopoliciamento ocorre em sintonia com o avanço das tecnologias e das ciências da saúde, reforçando essa vigilância ao longo da vida.

O que esperar, então, de sujeitos hipertensos, com taxas de colesterol elevado, com sobrepeso, sedentários, com dietas alimentares não balanceadas? Sob a perspectiva da filosofia do risco, seria a adoção de características do sujeito ativo, isto é, de atitudes de comprometimento consigo mesmo, esperando dele ações pró-ativas, comportamentos regulados, escolhas esteticamente adequadas, sem contar a construção de um corpus lingüístico, o qual atravessa os campos da nutrição, da medicina estética, da educação física e de outros saberes que passam a compor esse sujeito biológico.
A sociedade ocidental vive em uma situação paradoxal: "[...] livramo-nos da pressão da tradição, no desejo de sermos autônomos. Afirmamonos como indivíduos quando colocamos a tradição em segundo plano. No entanto, somos escravos de modelos que nos ensinam como devemos agir para sermos indivíduos mais auto-suficientes e vencedores em nossas atividades diárias. Ser indivíduo é seguir um modelo que nos é imposto. O individualismo vive uma exacerbação, uma vez que a modernidade inventou que cada sujeito se constrói a si próprio [...]". 30:1

As PES, sob a ótica do sujeito ativo, fortalecem a perspectiva do individualismo, que virou a norma, isto é, a ideologia dominante. ${ }^{30}$ Mesmo diante de tantas desigualdades sociais, os discursos analisados nas campanhas educativas, evocam a autonomia e a capacidade de escolha. Porém, essas escolhas são guiadas por especialistas, visto que, à medida que nos sentimos cada vez mais autônomos e donos de nosso destino, a grande parte das pessoas se sente desassistida, precisando de alguém que possa dizer o que fazer, qual a escolha certa.

\section{CONSIDERAÇÕES FINAIS}

Se, na atualidade, a saúde tornou-se juridicamente um direito e o Estado passou a ter esse dever constitucional, evidenciamos as tentativas de individualização, de promover o silenciamento do coletivo, de um Estado que passa cada vez mais delegar a seu cidadão suas atribuições e assim enaltecem a construção de subjetividades ativas, imersos em um novo higienismo, que apregoa a adoção insistente de hábitos saudáveis transitórios. Sob essa perspectiva, o sujeito cidadão e consumidor é instado a se posicionar nessa dualidade contingente do que é saudável ou não, segundo os atuais padrões culturais validados e legitimados socialmente.

Nesse mundo globalizado, de conexões capilarizadas entre o global e o local, as PES podem contribuir na formação de sujeitos prudentes, sujeitos responsáveis, sujeitos ativos que passam a consumir serviços e produtos de saúde, em mercados que avançam mais e mais, tendo como fim principal, qualidade de vida, corpo saudável, a saúde perfeita. Com isso verificamos que o individualismo se exacerbou em detrimento das dimensões coletivas e o Estado parece delegar crescentes responsabilidades a esse sujeito fragilizado. 
Ao sujeito ativo, muito mais que o papel de cidadão, aparece com veemência o sujeito consumidor. E essa ambivalência pode se disseminar pelos mais variados cenários, de modo heterogêneo, como os espaços de cuidado à saúde, através das pedagogias culturais, que fazem circular discursos com intencionalidade educativa, podendo contribuir nos processos de subjetivação atuais.

Assim, entendemos que as PES contemporâneas podem apresentar várias configurações, dentre elas as estratégias provenientes dos dispositivos de segurança, que contribuem para a formação de sujeitos ativos. No emaranhado de elementos discursivos, entrelaçados por inúmeras dimensões, por práticas de saúde construídas historicamente, não se pode mais imaginar relações de poder binarizadas e sim, múltiplas relações de poder entremeadas de interpelações, que delimitam condutas consideradas saudáveis para esse outro, alicerçadas em representações sociais e culturais e situadas em espaços e temporalidades particulares.

\section{REFERENNCIAS}

1. Bagnato MHS, Renovato RD. Práticas educativas em saúde: um território de saber, poder e produção de identidades. In: Deitos RA, Rodrigues RM organizadores. Estado, desenvolvimento, democracia \& políticas sociais. Cascavel (PR): EDUNIOESTE; 2006. p.87-104.

2. Caliman LV. Dominando corpos, conduzindo ações: genealogias do biopoder em Foucault [dissertação]. Rio de Janeiro (RJ): Universidade do Estado do Rio de Janeiro; 2001.

3. Foucault M. Security, territory, population. lectures at the College de France: 1977-1978. New York (US): Palgrave Macmillan; 2007.

4. Gordon C. Governmental rationality: an introduction. In: Burchell G, Gordon C, Miller, P. The Foucault effect. studies in governmentality with two lectures by and an interview with Michel Foucault. Chicago (US): The University of Chicago Press; 1991. p.1-51.

5. Foucault M. Dits et écrits. Paris (FR): Gallimard; 1994. v.4.

6. Foucault M. Microfísica do poder. $22^{\mathrm{a}}$ ed. Rio de Janeiro (RJ): Graal; 2006. p. 277-93.

7. Ramos OJ. O governo de si mesmo: modernidade pedagógica e encenações disciplinares do aluno liceal (último quartel do século XIX - meados do século XX). Lisboa (PT): EDUCA; 2003

8. Silva TT. A pedagogia psi e o governo do eu nos regimes neoliberais. In: Silva TT, organizador. Liberdades reguladas: a pedagogia construtivista e outras formas de governo do eu. $2^{\mathrm{a}}$ ed. Petrópolis (RJ): Vozes; 1999. p.7-13.

9. Foucault M. O Sujeito e o poder. In: Dreyfus H, Rabinow P. Michel Foucault, uma trajetória filosófica: para além do estruturalismo e da hermenêutica. Rio de Janeiro (RJ): Forense Universitária; 1995. p.231-249.

10. Foucault, M. História da sexualidade 2: o uso dos prazeres. 12a ed. Rio de Janeiro (RJ): Graal; 2007.

11. Foucault, M. Estratégia, poder-saber. Rio de Janeiro (RJ): Forense-Universitária; 2003.

12. Foucault M. Resumo dos cursos do Collège de France (1970-1982). Rio de Janeiro (RJ): Jorge Zahar; 1997.

13. Veiga-Neto A. Educação e governamentalidade neoliberal: novos dispositivos, novas subjetividades. In: Branco GC, Portocarrero V, organizadores. Retratos de Foucault. Rio de Janeiro (RJ): Nau; 2000. p.179-217.

14. Dean M. Governmentality: power and rule in modern society. London (UK): Sage; 1999.

15. Rose N. Governing the soul: the shaping of the private self. $2^{\mathrm{a}}$ ed. London (UK): Free Association Books; 1999.

16. Ewald F. Foucault, a norma e o direito. $2^{\mathrm{a}}$ ed. Lisboa (PT): Vega; 2000.

17. Rose N. The politics of life itself: biomedicine, power, subjectiviy in the twenty-first century. Princeton (US): Princeton University Press; 2006.

18. Camargo Jr KR. A biomedicina. Physis. 2005; 15(sup):177-201.

19. Gondra JG Artes de civilizar: medicina, higiene e educação escolar na Corte Imperial. Rio de Janeiro (RJ): EdUERJ; 2004.

20. Tesser CD. Medicalização social (I): o excessivo sucesso do epistemicídio moderno na saúde. Interface. 2006 Jan-Jun; 10(19):61-76.

21. Luz MT. Natural, racional, social: razão médica e racionalidade científica moderna. $2^{\mathrm{a}}$ ed. São Paulo (SP): Hucitec; 2004.

22. Rose N. The politics of life itself. Theor Cult Soc. 2001 Dec; 18(6):1-30.

23. Clarke AE, Shim JK, Mamo L, Fosket JR, Fishman JR. Biomedicalization: technoscientific transformations of health, illness, and U.S. biomedicine. Am Sociol Rev. 2003 Apr; 68(2):161-94.

24. Costa MV. Poder, discurso e política cultural: contribuição dos estudos culturais ao campo do currículo. In: Lopes AC, Macedo E, organizadores. Currículo: debates contemporâneos. São Paulo (SP): Cortez; 2002. p.133-49.

25. Bagnato MHS. Educação em saúde e cidadania: que discursos circulam nos espaços educativos. In: Camargo AMF, Mariguela M, organizadores. Cotidiano escolar: emergência e invenção. Piracicaba 
(SP): Jacintha Editores; 2007. p.163-82.

26. Santos LHS. Biopolíticas de HIV/AIDS no Brasil: uma análise dos anúncios televisivos das campanhas oficiais de prevenção (1986-2000) [tese]. Porto Alegre (RS): Universidade Federal do Rio Grande do Sul; 2002.

27. Renovato RD, Bagnato MHS, Missio L, Murback, SESL, Cruz LP, Bassinello, GAH. Significados e sentidos de saúde socializados por artefatos culturais: leituras das imagens de advertência nos maços de cigarro. Ciênc Saúde Coletiva. 2009; 14 (supl1):1599-608.
28. Souza MF. As campanhas governamentais e a propaganda ensinando a ser opticamente saudável [dissertação]. Canoas (RS): Universidade Luterana do Brasil; 2006.

29. Santos IUM. Cuidar e curar para governar: as campanhas de saúde na escola [dissertação]. Porto Alegre (RS): Universidade Federal do Rio Grande do Sul; 2004.

30. Bezerra B. Subjetividade humana na sociedade de indivíduos. 2007 [acesso 2007 Mai 25]. Disponível em: http://pepas.org/textos/entrevista_benilton_ bezerra.html 